\title{
Article \\ A Circulating Exosome RNA Signature Is a Potential Diagnostic Marker for Pancreatic Cancer, a Systematic Study
}

\author{
Yixing $W u^{1}$, Hongmei Zeng ${ }^{2}$, Qing $\mathrm{Yu}^{3}$, Huatian Huang ${ }^{4}$, Beatrice Fervers ${ }^{5,6}$, Zhe-Sheng Chen ${ }^{7}$ (D) \\ and Lingeng $\mathrm{Lu}^{8,9,10, *(D)}$
}

Citation: Wu, Y.; Zeng, H.; Yu, Q.; Huang, H.; Fervers, B.; Chen, Z.-S.; Lu, L. A Circulating Exosome RNA Signature Is a Potential Diagnostic Marker for Pancreatic Cancer, a Systematic Study. Cancers 2021, 13, 2565. https://doi.org/10.3390/ cancers13112565

Academic Editor: Adam E. Frampton

Received: 29 April 2021

Accepted: 19 May 2021

Published: 24 May 2021

Publisher's Note: MDPI stays neutral with regard to jurisdictional claims in published maps and institutional affiliations.

Copyright: (c) 2021 by the authors. Licensee MDPI, Basel, Switzerland. This article is an open access article distributed under the terms and conditions of the Creative Commons Attribution (CC BY) license (https:// creativecommons.org/licenses/by/ $4.0 /)$.
1 Department of Endocrinology, Second Affiliated Hospital of Guangzhou Medical University, Guangzhou 510260, China; wyxingz@126.com

2 National Central Cancer Registry, National Cancer Center/National Clinical Research Center for Cancer/Cancer Hospital, Chinese Academy of Medical Sciences and Peking Union Medical College, Beijing 100730, China; hongmeizeng2011@163.com

3 Center for Cancer and Blood Disorders, Children's National Medical Center, Washington, DC 20010, USA; qyu@cnmc.org

4 Department of Imaging, Guizhou Qianxinan People's Hospital, Xingyi 652400, China; huanght3702321@126.com

5 Département Prévention Cancer Environnement, Centre Léon Bérard-Université Lyon 1, 69008 Lyon, France; beatrice.fervers@lyon.unicancer.fr

6 UMR Inserm 1296 "Radiations: Défense, Santé, Environnement", Centre Léon Bérard, 69008 Lyon, France

7 Department of Pharmaceutical Sciences, St. John's University, New York, NY 11439, USA; chenz@stjohns.edu

8 Department of Chronic Disease Epidemiology, Yale School of Public Health, School of Medicine, New Haven, CT 06520, USA

9 Center for Biomedical Data Science, Yale University, 60 College Street, New Haven, CT 06520, USA

10 Yale Cancer Center, Yale University, 60 College Street, New Haven, CT 06520, USA

* Correspondence: lingeng.lu@yale.edu

Simple Summary: Most patients with pancreatic cancer are diagnosed at an advanced stage due to the lack of tools with high sensitivity and specificity for early detection. Aberrant gene expression occurs in pancreatic cancer, which can be packaged into nanoparticles (also known as exosomes or nano-sized extracellular vesicles) and then released into blood. In this study, we aimed to evaluate the diagnostic value of a circulating exosome RNA signature in pancreatic cancer. Our findings indicate that the circulating exosome RNA signature is a potential marker for the early detection or diagnosis of pancreatic cancer.

Abstract: Several exosome proteins, miRNAs and KRAS mutations have been investigated in the hope of carrying out the early detection of pancreatic cancer with high sensitivity and specificity, but they have proven to be insufficient. Exosome RNAs, however, have not been extensively evaluated in the diagnosis of pancreatic cancer. The purpose of this study was to investigate the potential of circulating exosome RNAs in pancreatic cancer detection. By retrieving RNA-seq data from publicly accessed databases, differential expression and random-effects meta-analyses were performed. The results showed that pancreatic cancer had a distinct circulating exosome RNA signature in healthy individuals, and that the top 10 candidate exosome RNAs could distinguish patients from healthy individuals with an area under the curve (AUC) of 1.0. Three (HIST2H2AA3, LUZP6 and HLA-DRA) of the 10 genes in exosomes had similar differential patterns to those in tumor tissues based on RNA-seq data. In the validation dataset, the levels of these three genes in exosomes displayed good performance in distinguishing cancer from both chronic pancreatitis (AUC $=0.815$ ) and healthy controls (AUC $=0.8558$, whereas a slight difference existed between chronic pancreatitis and healthy controls (AUC $=0.586$ ). Of the three genes, the level of HIST2H2AA3 was positively associated with $K R A S$ status. However, there was no significant difference in the levels of the three genes across the disease stages (stages I-IV). These findings indicate that circulating exosome RNAs have a potential early detection value in pancreatic cancer, and that a distinct exosome RNA signature exists in distinguishing pancreatic cancer from healthy individuals. 
Keywords: exosome; early detection; KRAS mutation; pancreatic cancer; RNA signature

\section{Introduction}

Live cell-secreted bilayer membranous extracellular nano-sized vesicles (also known as exosomes) carry bioactive macromolecules of proteins, DNA, RNA, lipids and metabolites that are exported out of and mirror their cells of origin. The exosome process was initially thought to be a mechanism utilized by cells for getting rid of 'wastes' that are toxic to them, favoring growth, malignant phenotypes or the avoidance of immune surveillance [1]. Accumulating evidence shows that exosomes play important roles in cell-to-cell communications through the transfer of bioactive donor-cell molecules to recipient cells, leading to physiological changes in the recipients and promoting tumor growth [2,3], and by which the donor cells may increase the number of their partners to orchestrate together against "unfavorable" environments [4]. Exosomes are secreted by living cells, and are frequently found in various body fluids, e.g., blood, saliva and urine $[5,6]$. These properties facilitate exosome collection, enabling the monitoring of disease progression and the response to treatment through minimally or non-invasive liquid biopsies. Furthermore, abnormal alterations in cells of origin can be found earlier by analyzing exosomes than by analyzing necrotic cell-derived products, such as circulating cell-free DNA/RNAs, which usually occurs at later disease stages. In addition, larger numbers of exosomes are secreted by tumor cells than by normal cells $[7,8]$, increasing the abundance of tumor-derived exosomes and making tumor information more detectable. Accumulating studies have shown the potential for the utilization of exosomes in the diagnosis/early detection, prognosis and monitoring of the treatment of human cancer, as well as for the engineering of vehicles to treat human cancer $[9,10]$.

Pancreatic ductal adenocarcinoma (PDAC) and closely-related variants comprise the major type $(>90 \%)$ of pancreatic cancer with a continuously rising incidence in the United States [11,12]. PDAC affects more than 45,000 individuals and leads to over 38,000 deaths each year in the United States [12]. In 2020, the incident cases of pancreatic cancer were 495,773 worldwide, and the number of deaths was increased approximately 2.38 -fold compared to year 1990 (466,003 vs. 196,000) [13]. Patients diagnosed at early stages with pancreatic cancer show considerable progress in treatment. Unfortunately, most patients still present with advanced disease, and less than $20 \%$ have resectable tumors [14-16], suggesting that no tools are available for early detection or diagnosis with sufficient sensitivity and specificity.

Pancreatic malignancy is a comprehensive consequence of genetic and epigenetic events. Hundreds of somatic mutations occur in PDAC with the highest frequency of $90 \%$ found in KRAS $[17,18]$. Animal models show that mutant KRAS ${ }^{\mathrm{G} 12 \mathrm{D}}$ or KRAS ${ }^{\mathrm{G} 12 \mathrm{~V}}$ is sufficient to initiate the development of PanINs, which progress to invasive metastatic PDAC after sufficient latency $[19,20]$. The presence of mutated KRAS DNA in both cell-free DNA and exosomes from PDAC suggests the potential of KRAS in the early detection of PDAC [21,22]. Recently, Yang et al. reported exosome KRAS DNA mutation in about $40 \%$ of pancreatic cancer patients [23]. Allenson et al. reported 66\% KRAS DNA mutations in pancreatic cancer patients vs. 7.4\% healthy controls [24]. Although some exosome proteins (CD44v6, Tspan8, EpCAM and CD104) in combination with several circulating exosome miRNA candidates have also shed light on the diagnosis of PDAC [22,25], these panels do not have enough sensitivity and specificity for the early detection of PDAC. More efforts are needed in order to explore novel markers for the detection of PDAC. Thus, the purpose of this study was to investigate circulating exosome RNAs as a potential marker of pancreatic cancer detection. 


\section{Results}

2.1. Differential Expression of Circulating Exosome RNAs between Pancreatic Cancer Patients and Healthy Controls

A large number of differentially expressed circulating exosome RNAs were identified in pancreatic cancer patients from the Shanghai study, and the fold-changes for the genes with significant differential expression are shown in Figure 1A.
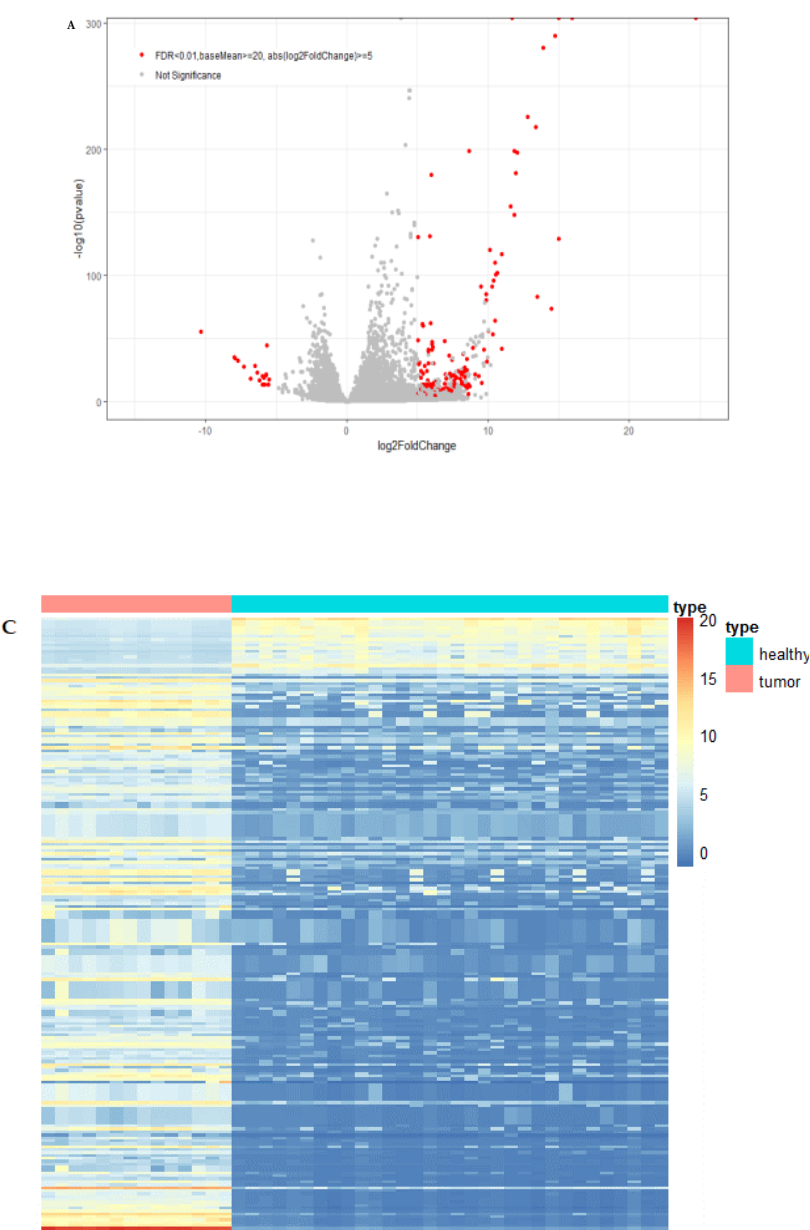

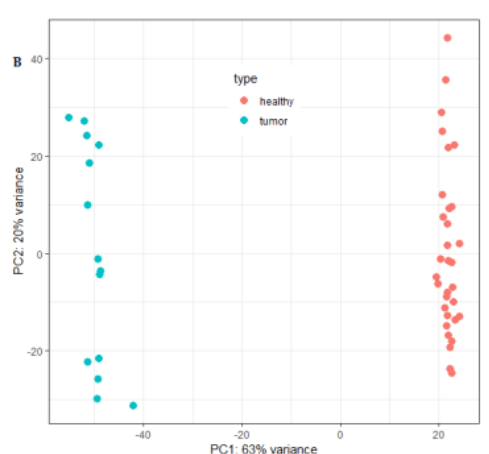

D

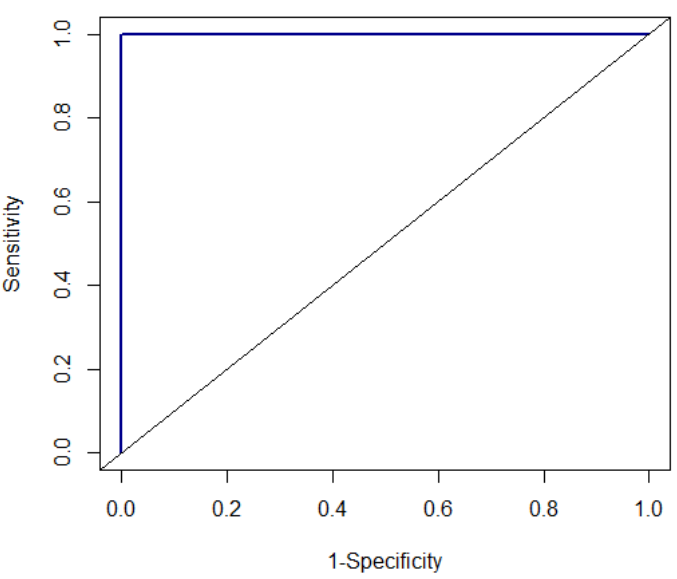

Figure 1. Differential expression of circulating exosome RNAs in pancreatic cancer patients and healthy individuals. (A) Volcano plot of differential circulating exosome RNAs. The red dots represent significant genes with baseMean $\geq 20$, the absolute value of $\log 2$ FoldChange $\geq 5$ and FDR $<0.01$, and the gray dots represent non-significant results. (B) PCA plot of circulating exosome RNAs showing the distance between the individuals. Light-coral dots represent healthy individuals and turquoise dots represent patients with pancreatic cancer. (C) Heatmap of significantly differential circulating exosome RNAs for patients with pancreatic cancer (light-coral bar) and healthy individuals (turquoise bar). The columns of the heatmap represent individuals, and the rows represent circulating exosome RNA genes. (D) Receiving operating characteristic (ROC) curve with the exosome RNAs of 10 candidate genes. AUC is the area under the curve.

Figure 1B is the PCA plot of RNA-seq data for circulating exosome RNAs. Pancreatic cancer patients showed a distinct circulating exosome RNA signature obtained from healthy individuals. The two groups were completely separated, particularly with regard to the first component, with a $63 \%$ variance, and each of the groups was clustered exclusively. The heatmap again shows that pancreatic cancer patients had a distinct circulating exosome RNA pattern in comparison to healthy individuals (Figure 1C).

To evaluate the performance of differential circulating exosome RNAs in distinguishing the health status of either pancreatic cancer patients or healthy controls, we used a random forest model and constructed an ROC curve with the normalized counts of the 
top 10 among the significantly differentially expressed genes (Figure 1D). The 10 circulating exosome RNAs showed a large area under the curve (AUC), with a value of 1.0 in distinguishing the patients from healthy controls.

To better understand the biological relevance of the differentially expressed RNAs in circulating exosomes derived from pancreatic cancer patients, we further performed IPA analysis based on the database released on 21 November 2018. The main results of IPA are shown in Table 1.

The top five canonical pathways were enriched, which included oxidative phosphorylation, mitochondrial dysfunction, the sirtuin signaling pathway, estrogen receptor signaling and the protein ubiquitination pathway. The top diseases and disorders were listed as cancer, organismal injury and abnormalities, infectious diseases, endocrine system disorders and gastrointestinal disease. The differentially expressed circulating exosome RNAs were statistically significantly enriched in five major characteristics of molecular and cellular functions, which included gene expression, cell death and survival, RNA post-transcriptional modification, protein synthesis and the cell cycle. Network analyses demonstrated several downregulated gene expression-related molecules of nuclear factors, zinc finger and RNA polymerases, an upregulated oncogene, PVT1, and dysregulated cell cycle-dependent kinases (Figure 2).

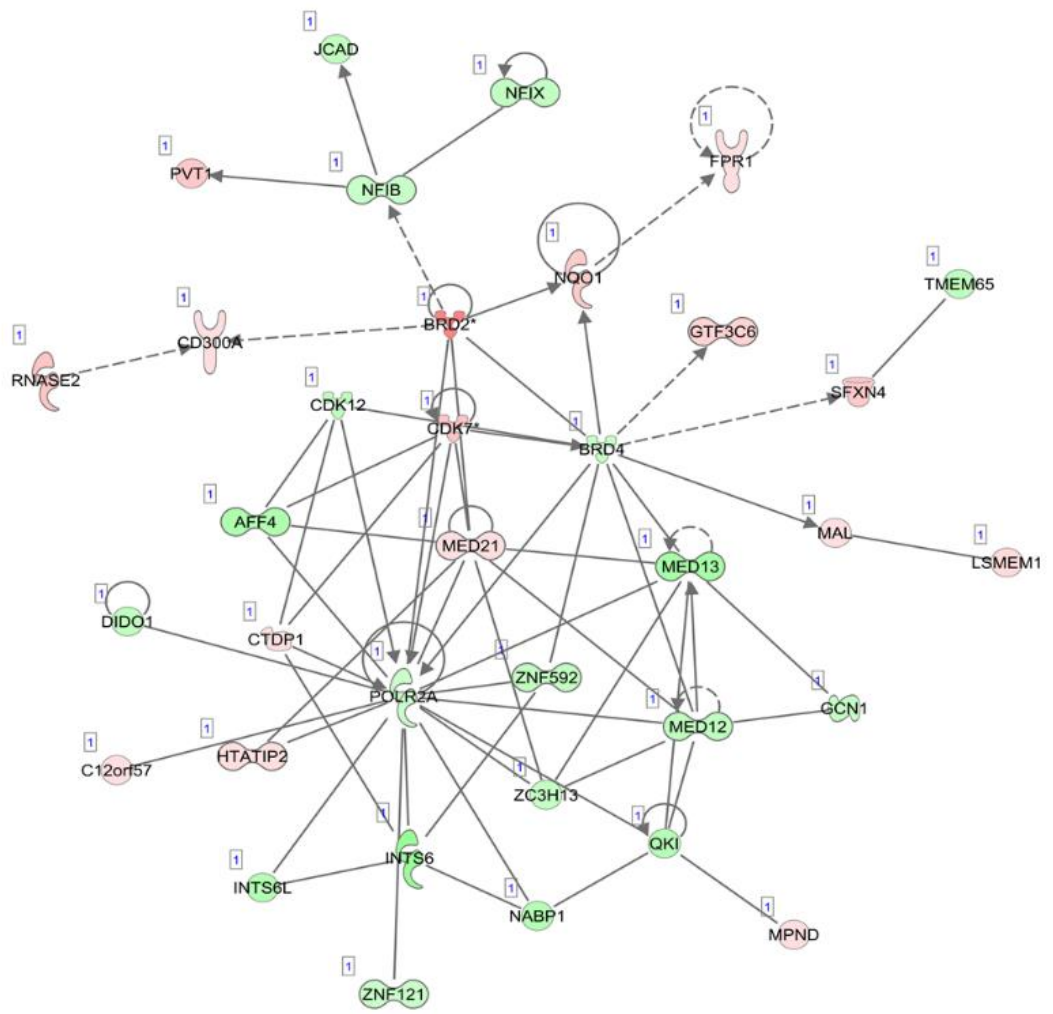

Figure 2. Illustration of the top network of differentially expressed transcripts, related to "gene expression", "RNA post-transcriptional modification" and "neurological diseases" in circulating exosome RNAs, compared between pancreatic cancer patients and healthy individuals. Red and green shading indicate the up- and downregulation of transcripts in circulating exosomes derived from patients with pancreatic cancer relative to healthy controls, respectively, with the color intensity corresponding to the degree of fold-change. Solid and dotted lines indicate direct and indirect relationships, respectively. 
Table 1. Summary of ingenuity pathway analysis (IPA) results.

\begin{tabular}{ccc}
\hline Name & $p$-Value & Overlap Genes \\
\hline Top Canonical Pathways & & \\
Oxidative Phosphorylation & $4.11 \times 10^{-18}$ & $51 / 109$ \\
Mitochondrial Dysfunction & $6.04 \times 10^{-17}$ & $65 / 171$ \\
Sirtuin Signaling Pathway & $4.20 \times 10^{-15}$ & $88 / 292$ \\
Estrogen Receptor Signaling & $1.25 \times 10^{-13}$ & $51 / 134$ \\
Protein Ubiquitination Pathway & $4.39 \times 10^{-11}$ & $75 / 271$ \\
Top Diseases and Disorders & & \\
Cancer & $3.73 \times 10^{-6}-1.06 \times 10^{-62}$ & 2644 \\
Organismal Injury and Abnormalities & $3.73 \times 10^{-6}-1.06 \times 10^{-62}$ & 2681 \\
Infectious Diseases & $3.61 \times 10^{-7}-1.47 \times 10^{-29}$ & 487 \\
Endocrine System Disorders & $3.09 \times 10^{-6}-2.55 \times 10^{-27}$ & 2081 \\
Gastrointestinal Disease & $3.09 \times 10^{-6}-5.50 \times 10^{-23}$ & 2243 \\
Top Molecular and Cellular Functions & & \\
Gene Expression & $1.12 \times 10^{-7}-1.97 \times 10^{-27}$ & 701 \\
Cell Death and Survival & $4.29 \times 10^{-6}-1.40 \times 10^{-22}$ & 961 \\
RNA Post-Transcriptional Modification & $6.14 \times 10^{-9}-9.99 \times 10^{-19}$ & 143 \\
Protein Synthesis & $3.93 \times 10^{-7}-9.13 \times 10^{-18}$ & 389 \\
Cell Cycle & $3.75 \times 10^{-6}-1.83 \times 10^{-17}$ & 523 \\
\hline
\end{tabular}

2.2. Differential Expression of Candidate Genes in Pancreas Tumors vs. Normal Tissues and Their Associations with Disease Stage

To further investigate whether the differential expression pattern found in circulating exosomes would be reproducible in pancreatic tumors vs. normal tissues, we searched two databases for the 10 candidate genes. First, we compared the expression levels of these genes based on the RNA-seq data in TCGA pancreatic adenocarcinoma $(n=179)$ and matched normal tissue plus the genotype-tissue expression in pancreas tissues $(n=171)$ using GEPIA (Figure 3). We found that there were statistically significant differences in the three genes HIST2H2AA3, LUZP6 and HLA-DRA comparing between pancreatic tumors and normal tissues $(p<0.01)$, with higher levels in tumors vs. normal tissues. The differences in the other seven genes were not statistically significant, although RN7SL1, MIR663AHG, GPM6A and FAM184B, for example, were higher in tumors vs. normal tissues $(p>0.01)$. Then, we retrieved gene expression array data from Oncomine ${ }^{\circledR}$ for the three coding genes HIST2H2AA3, LUZP6 and HLA-DRA. Random-effects meta-analysis results showed that the levels of $H I S T 2 H 2 A A 3$ showed a significant difference between pancreatic cancer and normal pancreas tissues, but those of LUZP6 and HLA-DRA did not (Figure 4). The fold change in $\log 2$ was 0.86 -fold (95\% CI: 0.14-1.58, $p=0.019$ ) for HIST2H2AA3, -0.17-fold (95\% CI: $-0.75-0.41, p=0.57)$ for LUZP6 and 0.84-fold (95\% CI: $-0.60-2.29$, $p=0.25)$ for $H L A-D R A$, respectively.

Finally, we further examined whether or not the three differential genes in tumors vs. normal tissues were associated with disease stages. Figure 5 shows the levels of the three genes HIST2H2AA3, LUZP6 and HLA-DRA across the disease stages. None of the three was significantly associated with the disease stage in pancreatic cancer $(p>0.05)$. 

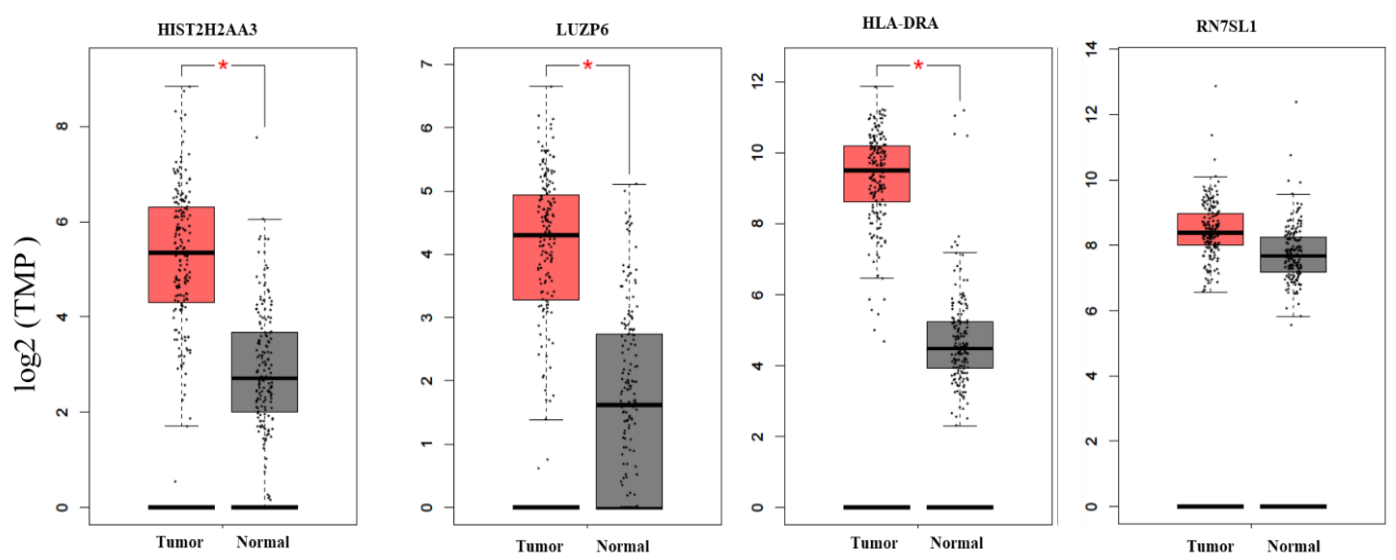

Figure 3. Boxplots of the candidate gene expression levels in pancreatic adenocarcinoma and normal pancreas tissues. The vertical $(y)$ axis is the gene expression level of transcripts per million (TPM) in $\log 2(\mathrm{TPM}+1)$, and the horizontal $(x)$ axis is the status of tissues (left box = tumor $(n=179)$ and right box = normal $(n=171)$ ). The solid line inside the box is the median and the box edges are the 25th and 75th quartiles (interquartile range, IQR). The whiskers are $1.5 \times$ IQRs. The black dots are the expression levels of the gene in individuals. ${ }^{*} p<0.01$.

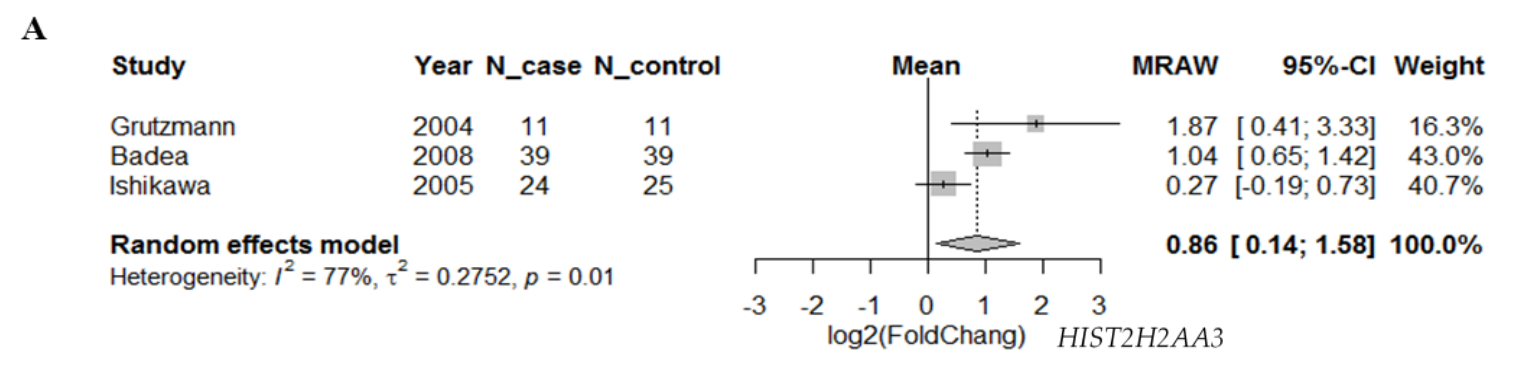

B

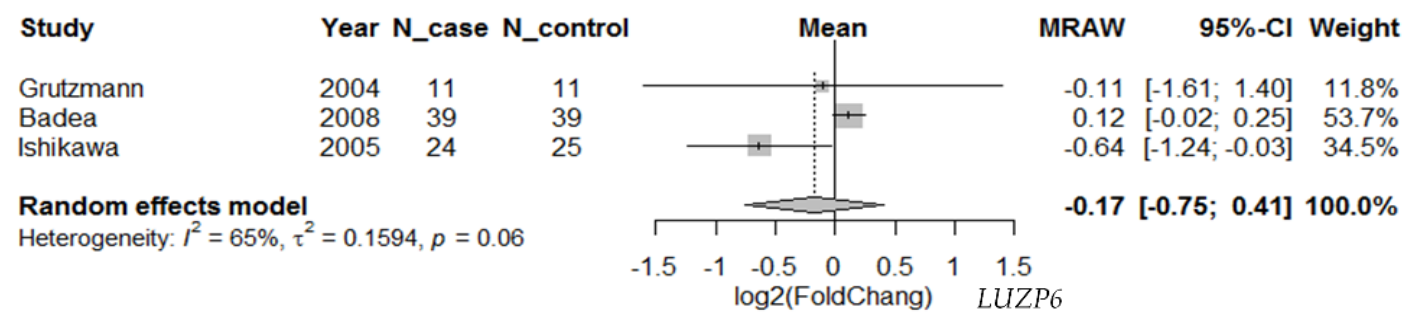

C

\begin{tabular}{|c|c|c|c|}
\hline Study & Year & J_case & N_con \\
\hline Grutzmann & 2004 & 11 & \\
\hline Badea & 2008 & 39 & \\
\hline Ishikawa & 2005 & 24 & \\
\hline
\end{tabular}

Random effects model

Heterogeneity: $I^{2}=91 \%, \tau^{2}=1.2388, p<0.01$

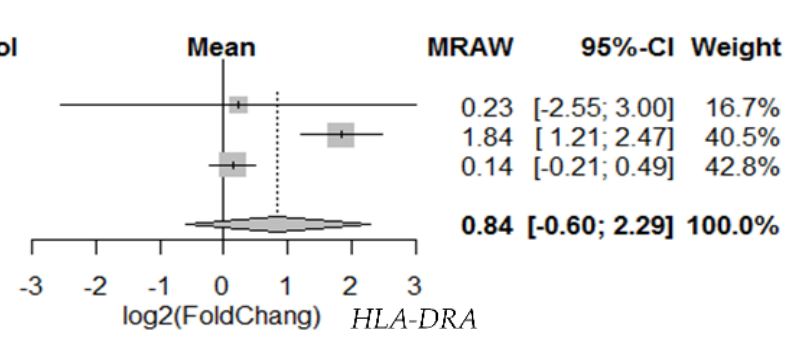

Figure 4. Forest plot of the differential gene expression in primary pancreatic cancer. Random-effects meta-analysis results of the fold change in log2 for HIST2H2AA3 (A), LUZP6 (B) and HLA-DRA (C) in primary pancreatic ductal adenocarcinoma vs. normal pancreas tissues. 

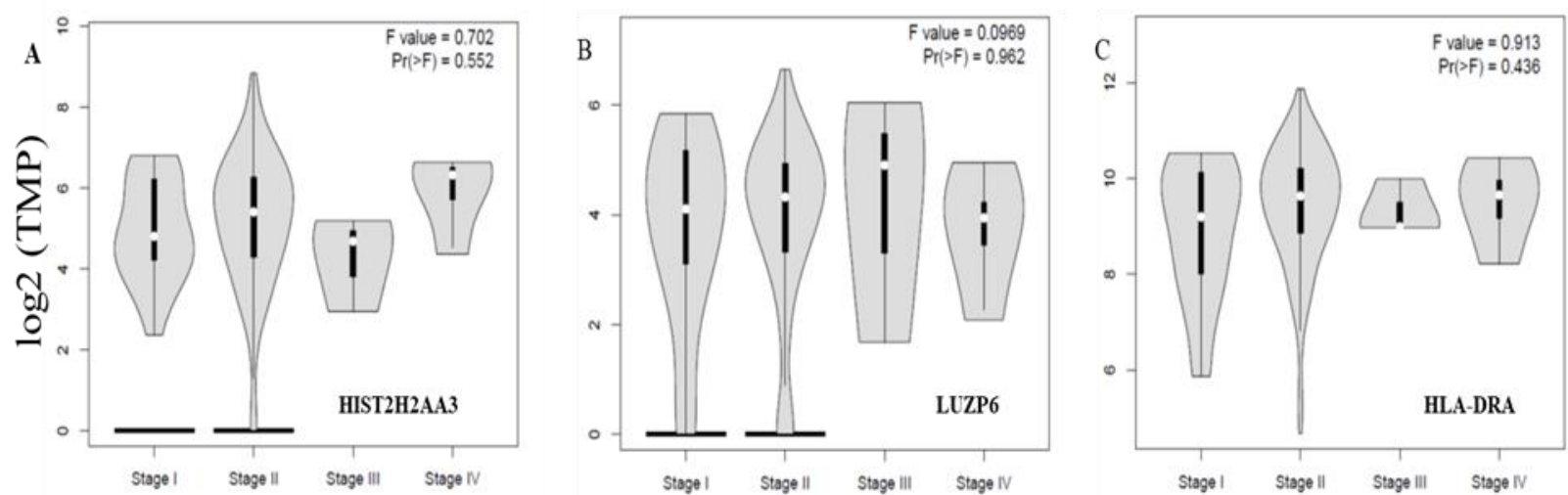

Figure 5. Violin plots of the three gene expression levels across the disease stages in pancreatic cancer. The vertical axis is the gene expression level of transcript per million (TPM) in log2 (TPM +1) for HIST2H2AA3 (A), LUZP6 (B) and HLA-DRA (C), respectively, and the horizontal axis is the disease stage. The violin shape is the frequency distribution of the gene expression levels; the inside boxplot represents the median (white dot), interquartile range (the box edge) and $95 \%$ confidence interval (the solid black line).

\subsection{Association of Candidate Gene Expressions with KRAS Mutation Status in Pancreas Tumors}

Activating KRAS mutations are present in over $90 \%$ of PDAC cases and are found in increasing frequency in developing PanIN lesions $[19,26]$. Thus, we wanted to further explore whether or not the levels of the three genes were KRAS mutation status-dependent. Using TCGA pancreatic cancer data, we found that between KRAS wild-type and mutants, there was a significant difference in the HIST2H2AA3 expression level $(p=0.001)$, but not in that of LUZP6 $(p=0.5)$ or HLA-DRA $(p=0.06)$ (Figure 6). Patients with KRAS mutation had a higher HIST2H2AA3 expression level than those with the wild-type gene $(2.7 \pm 0.38$ vs. $2.5 \pm 0.42, \log 10(\mathrm{FKPM}))$.
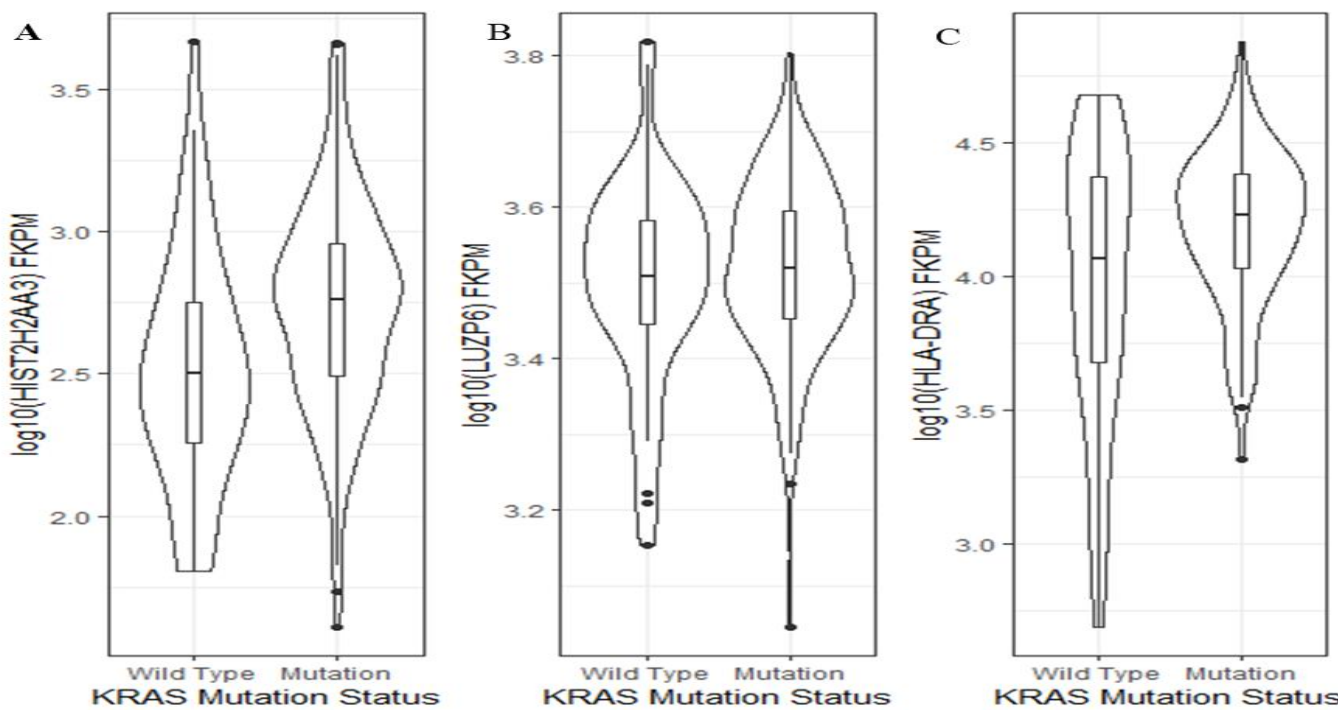

Figure 6. Violin plots of the three gene expression levels and $K R A S$ mutation status in pancreatic cancer. The vertical axis is the gene expression level in log10 (FKPM) for HIST2H2AA3 (A), LUZP6 (B) and HLA-DRA (C), respectively, and the horizontal axis is the KRAS mutation status. The violin shape is the frequency distribution of gene expression levels; the inside boxplot represents the median (black line), interquartile range (the box edge) and 95\% confidence interval (the solid black line). 


\subsection{Performance Validation of the HIST2H2AA3, LUZP6 and HLA-DRA Signature}

Given that HIST2H2AA3, LUZP6 and HLA-DRA expression levels were found to be independent of the disease stage, and that they were found to be statistically different between patients and healthy controls in both exosomes and tissues, we chose these three genes for performance validation in an independent study dataset. The ROC curves were constructed by creating logistic models, and the results are illustrated in Figure 7. The AUCs were 0.8558 (95\% CI: 0.82-0.89) for pancreatic cancer vs. healthy controls, 0.815 $(0.77-0.86)$ for pancreatic cancer vs. chronic pancreatitis, and 0.586 (0.51-0.66), respectively.
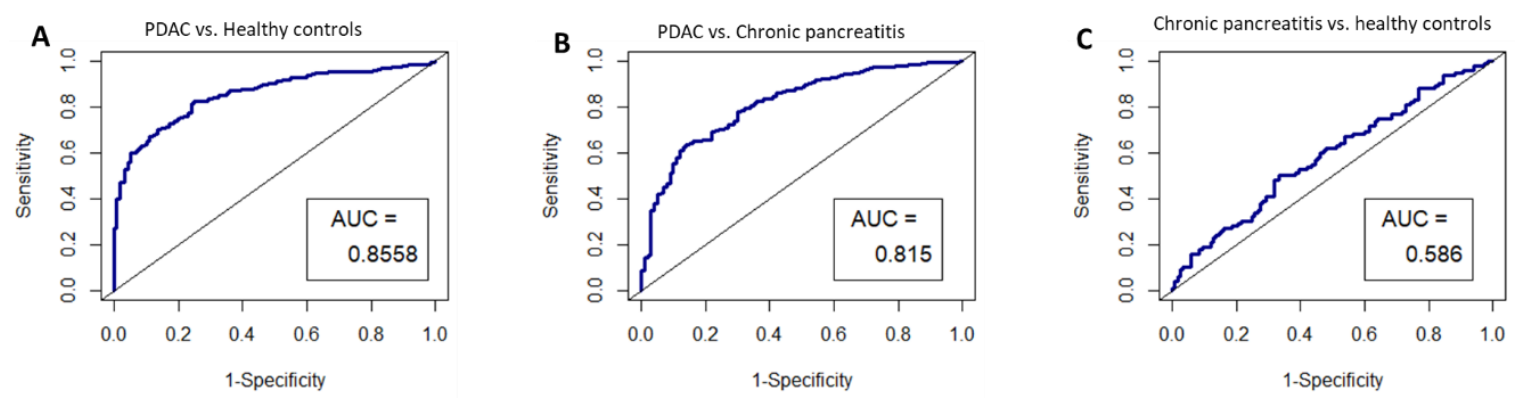

Figure 7. ROC curves for the circulating exosome RNA signature of HIST2H2AA3, LUZP6 and HLA-DRA in pancreatic cancer patients and healthy controls; (A) pancreatic cancer vs. healthy controls; (B) pancreatic cancer vs. chronic pancreatitis; and $(\mathbf{C})$ chronic pancreatitis vs. healthy controls, respectively. AUC is the area under the curve for the accuracy of the signature distinguishing the two groups.

\section{Discussion}

In this study, we evaluated the potential of circulating exosome RNAs as detection biomarkers in pancreatic cancer using publicly accessed datasets. We found that patients with pancreatic cancer had a distinct circulating exosome RNA signature in comparison to healthy controls. Ten of the top differentially expressed genes (five upregulated and five downregulated RNAs) were capable of distinguishing patients from healthy controls with an excellent performance (AUC $=1.0)$. We also found that three $(H I S T 2 H 2 A A 3$, LUZP6 and $H L A-D R A)$ of these 10 differential circulating exosome RNAs had a significantly higher level in tumors vs. normal tissues based on the RNA-seq data, suggesting that the pattern of these three genes in circulating exosomes was reproducible in tumor tissues. Using the levels of the three genes (HIST2H2AA3, LUZP6 and HLA-DRA) in exosomes as a signature, we obtained a high sensitivity and specificity (accuracy) in distinguishing patients with pancreatic cancer from healthy controls and from those with chronic pancreatitis in an independent study.

Exosomes are bilayer membrane nanosized vesicles (sized from 30-100 $\mathrm{nm}$ in diameter) that are actively secreted by live cells, which carry the contents of RNAs, DNAs, proteins and lipids from the cells of origin. Several studies have shown the discrepancies in RNA contents between the cells of origin and exosomes [27-31], suggesting that the bioactive molecular contents of exosomes are enriched. During exosome production, both microenvironment factors (such as stimuli and cell state) and RNA motifs may affect the compositions of RNAs in exosomes [32-37]. In addition to the relative abundance of small RNAs in exosomes, long non-coding RNAs (lncRNAs) and mRNAs are also enriched. Of the 10 candidate differential exosome RNAs, RN7SL1 and miR663AHG are lncRNAs. The potential of exosome lncRNAs as biomarkers and gene regulators has been demonstrated [38,39], which even at a low number of copies in the cells are more prone to be enriched in exosomes [27,40]. Thus, it is not surprising that the genes had differential expression in exosomes but not in cells. Similarly, Perez-Boza and colleagues also reported that mRNAs were enriched with more unique or exclusively mRNA genes in exosomes than in cells [27]. The coding mRNAs in exosomes could remain active, and once they are taken, could promote chemotherapy resistance in recipient cells [41]. Taken 
together, the uneven distribution of RNA species and fragments in exosomes derived from cells suggests that the delivery of RNAs into exosomes is selective. RNAs with some structural motifs (e.g., ACCAGCCU, CAGUGAGC and UAAUCCCA) are preferentially recognized by RNA-binding protein YB-1 and RNA methyltransferase NSUN2, which likely act as mediators, sorting specific mRNAs into exosomes [32]. However, the mechanism(s) underlying the selective packaging of RNAs in exosomes remains a challenge in the study of extracellular vesicles.

Interestingly, the top five enriched pathways for the differentially expressed RNAs in circulating exosomes were consistent with the findings of previous studies, which reported that these pathways were abnormal in pancreatic cancer. Metabolic reprogramming and mitochondrial dysfunction have been reported in pancreatic cancer, and by enhancing the nucleotide biosynthesis, the frequently mutated $K R A S$ gene stimulates cancer cell proliferation [42-45]. Targeting metabolic reprogramming pathways is a potential therapeutic strategy in the management of pancreatic cancer [42,44,46,47]. As a lysine deacetylase, sirtuin 1 is involved in the regulation of gene expression, such as that of TP53, and promotes the development of pancreatic cancer in cooperation with KRAS mutations [48]. Previous studies have demonstrated that reproductive factors and hormone usage increased the risk of pancreatic cancer, and that a high level of estrogen receptors elevates the mortality risk of the disease [49-53]. However, we found that on average, male PDAC patients survived 3.5 months longer than female patients (median: 21.4 (95\% CI: 19.4-37.1) for men vs. 17.9 (15.8-24.1) months for women, respectively), although the difference did not reach statistical significance (log-rank $p$-value $=0.37$ ) in this study (Supplementary Materials, Figure S1). A multivariate Cox model also excluded a significant association between sex and mortality in our previous study [54]. This was most likely because the sample size in this study was too small to replicate the general report that a higher mortality rate is observed in males than females [13]. An estrogen signaling system also exists in men, which plays an important role in the regulation of biological and pathological processes in both men and women $[55,56]$. Seeliger and colleagues reported no significant association between sex and estrogen signaling in PDAC [53]. However, they demonstrated significantly higher survival in patients with a low level of estrogen receptors in PDAC than those with a high level of estrogen receptors [53]. In addition, a recent study reported that ubiquitination signaling could activate $K R A S$ and promote macropinocytosis in pancreatic cancer [57]. Moreover, H. pylori infection is a risk factor for pancreatic cancer [58-61], which is also in agreement with the finding of infectious disease in the top diseases and disorders.

It has been reported that RN7SL1 inhibited the translation of TP53 by competing with HuR for binding to the $3^{\prime}$-UTR of TP53, consequently leading to cell cycle progression and suppressing cellular senescence and autophagy [62]. When unshielded RN7SL1 in circulating exosomes was taken up by the immune cells, it incited an inflammatory response by activating the PRR RIG-I and promoted tumor growth, metastasis and therapy resistance [63]. miR663AHG is a host gene of miR-663, which has been shown to be significantly downregulated in pancreatic cancer [64]. The overexpression of miR-663 led to attenuated proliferation and invasion by directly targeting eEF1A2 [64]. HIST2H2AA3 and HIST1H4K are histone gene variants, and have been shown to be dysregulated in human cancer [65]. HIST2H2AA3 was downregulated in N-nitrosodienthylamine-induced hepatocellular carcinoma [66], whereas it was upregulated in pancreatic cancer [67], suggesting that the aberrant HIST2H2AA3 expression in tumors was tissue-specific. In agreement with previous observations, we found that the level of HIST2H2AA3 in both exosome and cell compartments was higher in patients with pancreatic cancer than in healthy controls.

Immune escape is a hallmark of human cancer, including pancreatic cancer, and is a process in which many mechanisms are involved, such as the loss or downregulation of antigen presentation, immune checkpoint-induced CD8+ T cell exhaustion and the loss of tumor infiltration lymphocytes ("cold" tumors). Pandha and colleagues reported that the downregulation of MHC-I molecules was observed in pancreatic cancer, whereas 
HLA-DRA in MHC-II molecules was upregulated [68]. The findings in this study support the previous results beyond the trafficking of MHC-II HLA-DR molecules in exosomes [69].

Little is known about the biological relevance of leucine zipper protein 6 (LUZP6). The LUZP6 gene is located at chromosome 7, and its encoded protein is a putative tumor-self antigen. It may elicit an immune response in individuals with myeloproliferative disease who have received interferon alpha [70]. Another study showed that the LUZP6 protein was positive in the majority of glioblastoma [71], suggesting that it may also be related to tumorigenesis. Interestingly, LUZP6 RNA is enriched in salivary exosomes and, together with another three genes (IL1R2, VPS4B and CAP1) comprising an RNA signature, could distinguish high from low insulin resistance as an extracellular RNA marker [72].

Although the level of HIST2H2AA3, rather than that of LUZP6 and HLA-DRA, in tumor tissues was positively associated with KRAS mutation, there was no significant difference in the level of HIST2H2AA3, LUZP6 or HLA-DRA expression across the disease stages. This finding suggests that these markers may be more reliable than the frequency of KRAS mutations in the early detection of pancreatic cancer, given that the frequency of KRAS mutations increases with the disease stages. Moreover, in three independent gene expression array studies with a relatively small sample size, the differential expression of HIST2H2AA3 was reproducible in the tumors vs. normal pancreas tissues, but those of LUZP6 and HLA-DRA were not.

There are some limitations in this study. One is that the plasma samples were collected from patients who presented clinical manifestations of the disease in the Shanghai study. Another is the fact that no disease stage information or other demographic information was available for the patients and healthy controls in the circulating exosome RNA analyses in the Shanghai study. In addition, smoking status was also unavailable in the Shanghai study, which is considered to be an established risk factor for pancreatic cancer [73]; thus, we cannot evaluate how smoking status affects the RNA molecules in circulating exosomes. However, the findings of this study emphasize the value of further investigating circulating exosome RNAs as potential markers in pancreatic cancer detection. Longitudinal studies should be conducted to further evaluate this method's sensitivity and specificity, as well as its positive and negative predictive values (PPV, NPV) for disease screening, particularly in individuals at high risk $[74,75]$.

\section{Materials and Methods}

\subsection{Data Sources}

Two Gene Expression Omnibus (GEO) datasets (GSE100232 and GSE100206) for the discovery of exosome RNA signatures and one GSE133684 dataset for validation were retrieved from the National Center for Biotechnology Information (NCBI) (https: / / www. ncbi.nlm.nih.gov) (11 March 2019 for GSE100232 and GSE100206 and 12 March 2021 for GSE133684). The methods used for exosome isolation from plasma biospecimens, exosome identification and RNA sequencing for these three GEO datasets have been described as elsewhere [76-78]. Briefly, using an ultracentrifuge, exosomes were isolated from plasma samples, followed by size and morphology characterization using transmission electron microscopy and exosome surface marker CD63 detection using Western blotting. Total RNAs from each isolated exosome sample were purified using Trizol reagent (Invitrogen, Waltham, MA, USA). After DNase I treatment, RNA-seq libraries were prepared and RNA sequencing was performed using an Illumina sequencing platform. GSE100232 contains RNA-seq data from 14 patients with pancreatic cancer, and GSE100206 contains data from 32 healthy individuals [76,77]. GSE133684 consisted of data from 284 pancreatic cancer patients, 100 chronic pancreatitis patients and 117 healthy controls [78].

The Cancer Genome Altas (TCGA) and Genotype-Tissue Expression (GTEx) RNA-seq data were also used to compare the expression of genes in pancreatic cancer vs. normal tissues using Gene Expression Profiling Interactive Analysis (GEPIA2) (http:/ /gepia2 .cancer-pku.cn) (27 March 2019). The demographic information on the patients in TCGA data has been described elsewhere previously [54]. The differential expressions of candidate 
genes, which were determined by whole genome expression arrays, were retrieved from the gene expression dataset Oncomine ${ }^{\mathrm{TM}}$ (https: / / www.oncomine.org) (28 March 2019) (ThermoFisher Scientific Inc., Waltham, MA, USA) using the parameters of differential analysis (cancer vs. normal), cancer type (pancreatic ductal adenocarcinoma), sample type (clinical specimen), data type (mRNA) and gene (e.g., HIST2H2AA3) and total subjects $\geq 20$.

\subsection{Statistical and Bioinformatics Analyses}

Statistical analyses were performed using R package 3.5 (https: / / www.r-project.org) (21 March 2020). The differential expression of circulating exosome RNAs, compared between pancreatic cancer patients and healthy individuals, was analyzed using the DESeq2 package, in which the negative binomial distribution was applied. Principal component analysis (PCA) was performed to obtain the top 2 components with the largest variances, after data transformation and batch effect removal, for PCA plot visualization. Heatmaps were constructed based on the significant differential expression genes with adjusted $p$ values greater than 0.01 , and the means of normalized counts of all samples (baseMean) $\geq 20$ FPKM (fragments per kilobase of transcript per million mapped reads), and the absolute value of $\log 2$ FoldChange $\geq 5$. The top 10 candidate genes ( 5 upregulated genes, consisting of HIST2H2AA3, HIST1H4K, HLD-DRA, RN7SL1 and LUZP6, and 5 downregulated genes consisting of FAM184B, FGF23, NEUROD2, miR663AHG and GPM6A in the circulating exosome RNAs of pancreatic cancer patients) with significant differential expression were selected for receiving operating characteristic (ROC) curve analysis using the random forest algorithm, in which the sensitivity and specificity were calculated. In the validation stage, a logistic model was used for the construction of ROC curves, using HIST2H2AA3, LUZP6 and HLA-DRA mRNA levels in exosomes. Ingenuity pathway analysis (IPA) (Qiagen Bioinformatics, Redwood City, CA, USA) was performed for the differentially expressed genes with adjusted $p$-values $<0.01$, and baseMean $\geq 20$ FPKM, and the absolute value of $\log 2$ FoldChange $\geq 2$ (to include more genes in the IPA analysis).

A random-effects model in the meta-analysis was performed to determine the fold change in gene expression array-based differential gene expression compared between pancreatic cancer and normal tissues, following a methodology that has been previously described elsewhere $[79,80]$. A $p$-value of less than 0.05 was considered statistically significant if not specified.

\section{Conclusions}

This study revealed a distinct exosome RNA signature in plasma, which was capable of distinguishing pancreatic cancer patients from healthy individuals. The top 10 candidate exosome RNAs showed a high performance in the diagnosis of pancreatic cancer. Of these, three upregulated genes (HIST2H2AA3, LUZP6 and HLA-DRA) in exosomes also showed the same pattern in pancreatic tumors vs. normal pancreas tissue. There were no significant differences in the levels of these three genes across the disease stages, although HIST2H2AA3 expression was associated with KRAS mutation status. These findings suggest that circulating exosome RNAs are potential markers in the detection of pancreatic cancer. Further independent studies with a relatively large sample size and the inclusion of individuals with non-cancer diseases (e.g., chronic pancreatitis), or conducted in populations at high risk of pancreatic cancer, are warranted.

Supplementary Materials: The following are available online at https: / www.mdpi.com/article / 10.3390/cancers13112565/s1, Figure S1: Kaplan-Meier overall survival curves stratified by sex in pancreatic cancer. Male patients showed superior overall survival in comparison with female patients. The median survival values were 21.4 (95\% CI: 19.4-37.1) months for men and 17.9 (95\% CI: 15.8-24.1) months for women, respectively. On average, male patients survived approximately 3.5 months longer than female patients. However, the difference was not statistically significant $(\log$-rank $p$-value $=0.37)$. 
Author Contributions: Conceptualization, L.L.; methodology, Y.W., H.Z., Q.Y. and L.L.; formal analysis, Y.W., H.Z. and L.L.; investigation, Y.W., H.Z., Q.Y., H.H. and L.L.; resources, L.L.; data curation, Y.W., H.Z., Q.Y., H.H., B.F., Z.-S.C. and L.L.; writing-original draft preparation, Y.W., H.Z., Q.Y., H.H. and L.L.; writing-review and editing, B.F., Z.-S.C. and L.L.; visualization, Y.W., H.Z., Q.Y., H.H., B.F., Z.-S.C. and L.L.; supervision, L.L. All authors have read and agreed to the published version of the manuscript.

Funding: This research received no external funding.

Institutional Review Board Statement: No formal consent is required for this type of study. The ethical standards of the institutional and/or national research committee and the 1964 Helsinki declaration and its later amendments or comparable ethical standards were followed in performing all procedures in this study involving human subjects. The study presented here complies with the current laws of the United States of America.

Informed Consent Statement: Not applicable.

Data Availability Statement: All data used in this work are publicly accessible as described in the materials and Methods.

Acknowledgments: We thank individuals for generously donating their tumor tissues for The Cancer Genome Atlas program and blood for exosome RNA studies. We also thank the researchers for their generated data deposited in the GEO repository.

Conflicts of Interest: The authors declare no conflict of interest.

\section{References}

1. Azmi, A.S.; Bao, B.; Sarkar, F.H. Exosomes in cancer development, metastasis, and drug resistance: A comprehensive review. Cancer Metastasis Rev. 2013, 32, 623-642. [CrossRef]

2. Valadi, H.; Ekstrom, K.; Bossios, A.; Sjostrand, M.; Lee, J.J.; Lotvall, J.O. Exosome-mediated transfer of mRNAs and microRNAs is a novel mechanism of genetic exchange between cells. Nat. Cell Biol. 2007, 9, 654-659. [CrossRef]

3. Skog, J.; Wurdinger, T.; van Rijn, S.; Meijer, D.H.; Gainche, L.; Sena-Esteves, M.; Curry, W.T., Jr.; Carter, B.S.; Krichevsky, A.M.; Breakefield, X.O. Glioblastoma microvesicles transport RNA and proteins that promote tumour growth and provide diagnostic biomarkers. Nat. Cell Biol. 2008, 10, 1470-1476. [CrossRef]

4. Costa-Silva, B.; Aiello, N.M.; Ocean, A.J.; Singh, S.; Zhang, H.; Thakur, B.K.; Becker, A.; Hoshino, A.; Mark, M.T.; Molina, H.; et al. Pancreatic cancer exosomes initiate pre-metastatic niche formation in the liver. Nat. Cell Biol. 2015, 17, 816-826. [CrossRef] [PubMed]

5. Inal, J.M.; Kosgodage, U.; Azam, S.; Stratton, D.; Antwi-Baffour, S.; Lange, S. Blood/plasma secretome and microvesicles. Biochim. Biophys. Acta 2013, 1834, 2317-2325. [CrossRef] [PubMed]

6. Lasser, C. Identification and analysis of circulating exosomal microRNA in human body fluids. Methods Mol. Biol. 2013, 1024, 109-128. [CrossRef] [PubMed]

7. Parolini, I.; Federici, C.; Raggi, C.; Lugini, L.; Palleschi, S.; De Milito, A.; Coscia, C.; Iessi, E.; Logozzi, M.; Molinari, A.; et al. Microenvironmental $\mathrm{pH}$ is a key factor for exosome traffic in tumor cells. J. Biol. Chem. 2009, 284, 34211-34222. [CrossRef]

8. Smyth, T.J.; Redzic, J.S.; Graner, M.W.; Anchordoquy, T.J. Examination of the specificity of tumor cell derived exosomes with tumor cells in vitro. Biochim. Biophys. Acta 2014, 1838, 2954-2965. [CrossRef]

9. Vaksman, O.; Trope, C.; Davidson, B.; Reich, R. Exosome-derived miRNAs and ovarian carcinoma progression. Carcinogenesis 2014, 35, 2113-2120. [CrossRef] [PubMed]

10. Sugimachi, K.; Matsumura, T.; Hirata, H.; Uchi, R.; Ueda, M.; Ueo, H.; Shinden, Y.; Iguchi, T.; Eguchi, H.; Shirabe, K.; et al. Identification of a bona fide microRNA biomarker in serum exosomes that predicts hepatocellular carcinoma recurrence after liver transplantation. Br. J. Cancer 2015, 112, 532-538. [CrossRef]

11. Risch, H.A. Pancreatic cancer: Helicobacter pylori colonization, N-nitrosamine exposures, and ABO blood group. Mol. Carcinog. 2012, 51, 109-118. [CrossRef]

12. Siegel, R.L.; Miller, K.D.; Jemal, A. Cancer statistics, 2019. CA Cancer J. Clin. 2019, 69, 7-34. [CrossRef] [PubMed]

13. Sung, H.; Ferlay, J.; Siegel, R.L.; Laversanne, M.; Soerjomataram, I.; Jemal, A.; Bray, F. Global cancer statistics 2020: GLOBOCAN estimates of incidence and mortality worldwide for 36 cancers in 185 countries. CA Cancer J. Clin. 2021. [CrossRef] [PubMed]

14. Hezel, A.F.; Kimmelman, A.C.; Stanger, B.Z.; Bardeesy, N.; Depinho, R.A. Genetics and biology of pancreatic ductal adenocarcinoma. Genes Dev. 2006, 20, 1218-1249. [CrossRef]

15. Pitt, H.A. Curative treatment for pancreatic neoplasms: Standard resection. Surg. Clin. N. Am. 1995, 75, 891-904. [CrossRef]

16. AGA. American gastroenterological association medical position statement: Epidemiology, diagnosis, and treatment of pancreatic ductal adenocarcinoma. Gastroenterology 1999, 117, 1463-1484. [CrossRef]

17. Lennerz, J.K.; Stenzinger, A. Allelic ratio of KRAS mutations in pancreatic cancer. Oncologist 2015, 20, e8-e9. [CrossRef] 
18. Cui, N.; Zhang, J.; Huang, H.; Lu, L. Epigenetic regulator ARID1A and stem cell transcription factor SOX9 in the maintenance of pancreatic ductal cell differentiation state and development of intraductal papillary mucinous neoplasia (IPMN) and pancreatic ductal adenocarcinoma (PDAC). Trans. Cancer Res. 2018, 7, S748-S751. [CrossRef]

19. Morris, J.P.t.; Wang, S.C.; Hebrok, M. KRAS, Hedgehog, Wnt and the twisted developmental biology of pancreatic ductal adenocarcinoma. Nat. Rev. Cancer 2010, 10, 683-695. [CrossRef] [PubMed]

20. Guerra, C.; Schuhmacher, A.J.; Canamero, M.; Grippo, P.J.; Verdaguer, L.; Perez-Gallego, L.; Dubus, P.; Sandgren, E.P.; Barbacid, M. Chronic pancreatitis is essential for induction of pancreatic ductal adenocarcinoma by K-Ras oncogenes in adult mice. Cancer Cell 2007, 11, 291-302. [CrossRef]

21. Earl, J.; Garcia-Nieto, S.; Martinez-Avila, J.C.; Montans, J.; Sanjuanbenito, A.; Rodriguez-Garrote, M.; Lisa, E.; Mendia, E.; Lobo, E.; Malats, N.; et al. Circulating tumor cells (Ctc) and kras mutant circulating free Dna (cfdna) detection in peripheral blood as biomarkers in patients diagnosed with exocrine pancreatic cancer. BMC Cancer 2015, 15, 797. [CrossRef] [PubMed]

22. Melo, S.A.; Luecke, L.B.; Kahlert, C.; Fernandez, A.F.; Gammon, S.T.; Kaye, J.; LeBleu, V.S.; Mittendorf, E.A.; Weitz, J.; Rahbari, N.; et al. Glypican-1 identifies cancer exosomes and detects early pancreatic cancer. Nature 2015, 523, 177-182. [CrossRef]

23. Yang, S.; Che, S.P.; Kurywchak, P.; Tavormina, J.L.; Gansmo, L.B.; Correa de Sampaio, P.; Tachezy, M.; Bockhorn, M.; Gebauer, F.; Haltom, A.R.; et al. Detection of mutant KRAS and TP53 DNA in circulating exosomes from healthy individuals and patients with pancreatic cancer. Cancer Biol. Ther. 2017, 1-8. [CrossRef]

24. Allenson, K.; Castillo, J.; San Lucas, F.A.; Scelo, G.; Kim, D.U.; Bernard, V.; Davis, G.; Kumar, T.; Katz, M.; Overman, M.J.; et al. High Prevalence of Mutant KRAS in Circulating Exosome-derived DNA from Early Stage Pancreatic Cancer Patients. Ann. Oncol. 2017. [CrossRef] [PubMed]

25. Madhavan, B.; Yue, S.; Galli, U.; Rana, S.; Gross, W.; Muller, M.; Giese, N.A.; Kalthoff, H.; Becker, T.; Buchler, M.W.; et al. Combined evaluation of a panel of protein and miRNA serum-exosome biomarkers for pancreatic cancer diagnosis increases sensitivity and specificity. Int. J. Cancer 2015, 136, 2616-2627. [CrossRef] [PubMed]

26. Kanda, M.; Matthaei, H.; Wu, J.; Hong, S.M.; Yu, J.; Borges, M.; Hruban, R.H.; Maitra, A.; Kinzler, K.; Vogelstein, B.; et al. Presence of somatic mutations in most early-stage pancreatic intraepithelial neoplasia. Gastroenterology 2012, 142, 730-733.e739. [CrossRef] [PubMed]

27. Perez-Boza, J.; Lion, M.; Struman, I. Exploring the RNA landscape of endothelial exosomes. RNA 2018, 24, 423-435. [CrossRef] [PubMed]

28. Crescitelli, R.; Lasser, C.; Szabo, T.G.; Kittel, A.; Eldh, M.; Dianzani, I.; Buzas, E.I.; Lotvall, J. Distinct RNA profiles in subpopulations of extracellular vesicles: Apoptotic bodies, microvesicles and exosomes. J. Extracell Vesicles 2013, 2. [CrossRef]

29. Miranda, K.C.; Bond, D.T.; Levin, J.Z.; Adiconis, X.; Sivachenko, A.; Russ, C.; Brown, D.; Nusbaum, C.; Russo, L.M. Massively parallel sequencing of human urinary exosome/microvesicle RNA reveals a predominance of non-coding RNA. PLoS ONE 2014, 9, e96094. [CrossRef] [PubMed]

30. Lazaro-Ibanez, E.; Lunavat, T.R.; Jang, S.C.; Escobedo-Lucea, C.; Oliver-De La Cruz, J.; Siljander, P.; Lotvall, J.; Yliperttula, M. Distinct prostate cancer-related mRNA cargo in extracellular vesicle subsets from prostate cell lines. BMC Cancer 2017, 17, 92. [CrossRef] [PubMed]

31. Jenjaroenpun, P.; Kremenska, Y.; Nair, V.M.; Kremenskoy, M.; Joseph, B.; Kurochkin, I.V. Characterization of RNA in exosomes secreted by human breast cancer cell lines using next-generation sequencing. PeerJ 2013, 1, e201. [CrossRef]

32. Kossinova, O.A.; Gopanenko, A.V.; Tamkovich, S.N.; Krasheninina, O.A.; Tupikin, A.E.; Kiseleva, E.; Yanshina, D.D.; Malygin, A.A.; Ven'yaminova, A.G.; Kabilov, M.R.; et al. Cytosolic YB-1 and NSUN2 are the only proteins recognizing specific motifs present in mRNAs enriched in exosomes. Biochim. Biophys. Acta Proteins Proteom. 2017, 1865, 664-673. [CrossRef] [PubMed]

33. Shurtleff, M.J.; Temoche-Diaz, M.M.; Karfilis, K.V.; Ri, S.; Schekman, R. Y-box protein 1 is required to sort microRNAs into exosomes in cells and in a cell-free reaction. Elife 2016, 5, e19276. [CrossRef]

34. Santangelo, L.; Giurato, G.; Cicchini, C.; Montaldo, C.; Mancone, C.; Tarallo, R.; Battistelli, C.; Alonzi, T.; Weisz, A.; Tripodi, M. The RNA-Binding Protein SYNCRIP Is a Component of the Hepatocyte Exosomal Machinery Controlling MicroRNA Sorting. Cell Rep. 2016, 17, 799-808. [CrossRef]

35. Villarroya-Beltri, C.; Gutierrez-Vazquez, C.; Sanchez-Cabo, F.; Perez-Hernandez, D.; Vazquez, J.; Martin-Cofreces, N.; MartinezHerrera, D.J.; Pascual-Montano, A.; Mittelbrunn, M.; Sanchez-Madrid, F. Sumoylated hnRNPA2B1 controls the sorting of miRNAs into exosomes through binding to specific motifs. Nat. Commun. 2013, 4, 2980. [CrossRef]

36. Li, L.; Li, C.; Wang, S.; Wang, Z.; Jiang, J.; Wang, W.; Li, X.; Chen, J.; Liu, K.; Li, C.; et al. Exosomes Derived from Hypoxic Oral Squamous Cell Carcinoma Cells Deliver miR-21 to Normoxic Cells to Elicit a Prometastatic Phenotype. Cancer Res. 2016, 76, 1770-1780. [CrossRef] [PubMed]

37. Challagundla, K.B.; Wise, P.M.; Neviani, P.; Chava, H.; Murtadha, M.; Xu, T.; Kennedy, R.; Ivan, C.; Zhang, X.; Vannini, I.; et al. Exosome-mediated transfer of microRNAs within the tumor microenvironment and neuroblastoma resistance to chemotherapy. $J$. Natl. Cancer Inst. 2015, 107. [CrossRef]

38. Ahadi, A.; Brennan, S.; Kennedy, P.J.; Hutvagner, G.; Tran, N. Long non-coding RNAs harboring miRNA seed regions are enriched in prostate cancer exosomes. Sci. Rep. 2016, 6, 24922. [CrossRef] [PubMed]

39. Isin, M.; Uysaler, E.; Ozgur, E.; Koseoglu, H.; Sanli, O.; Yucel, O.B.; Gezer, U.; Dalay, N. Exosomal lncRNA-p21 levels may help to distinguish prostate cancer from benign disease. Front. Genet. 2015, 6, 168. [CrossRef] 
40. Gezer, U.; Ozgur, E.; Cetinkaya, M.; Isin, M.; Dalay, N. Long non-coding RNAs with low expression levels in cells are enriched in secreted exosomes. Cell Biol. Int. 2014, 38, 1076-1079. [CrossRef] [PubMed]

41. Lobb, R.J.; van Amerongen, R.; Wiegmans, A.; Ham, S.; Larsen, J.E.; Moller, A. Exosomes derived from mesenchymal non-small cell lung cancer cells promote chemoresistance. Int. J. Cancer 2017, 141, 614-620. [CrossRef]

42. Masoud, R.; Reyes-Castellanos, G.; Lac, S.; Garcia, J.; Dou, S.; Shintu, L.; Abdel Hadi, N.; Gicquel, T.; El Kaoutari, A.; Dieme, B.; et al. Targeting Mitochondrial Complex I Overcomes Chemoresistance in High OXPHOS Pancreatic Cancer. Cell Rep. Med. 2020, 1, 100143. [CrossRef] [PubMed]

43. Vaziri-Gohar, A.; Zarei, M.; Brody, J.R.; Winter, J.M. Metabolic Dependencies in Pancreatic Cancer. Front. Oncol. 2018, 8, 617. [CrossRef]

44. Reyes-Castellanos, G.; Masoud, R.; Carrier, A. Mitochondrial Metabolism in PDAC: From Better Knowledge to New Targeting Strategies. Biomedicines 2020, 8, 270. [CrossRef] [PubMed]

45. Nie, K.; Li, J.; He, X.; Wang, Y.; Zhao, Q.; Du, M.; Sun, H.; Wang, J.; Lyu, J.; Fang, H.; et al. COX6B2 drives metabolic reprogramming toward oxidative phosphorylation to promote metastasis in pancreatic ductal cancer cells. Oncogenesis 2020, 9, 51. [CrossRef]

46. Qin, C.; Yang, G.; Yang, J.; Ren, B.; Wang, H.; Chen, G.; Zhao, F.; You, L.; Wang, W.; Zhao, Y. Metabolism of pancreatic cancer: Paving the way to better anticancer strategies. Mol. Cancer 2020, 19, 50. [CrossRef]

47. Valle, S.; Alcala, S.; Martin-Hijano, L.; Cabezas-Sainz, P.; Navarro, D.; Munoz, E.R.; Yuste, L.; Tiwary, K.; Walter, K.; Ruiz-Canas, L.; et al. Exploiting oxidative phosphorylation to promote the stem and immunoevasive properties of pancreatic cancer stem cells. Nat. Commun. 2020, 11, 5265. [CrossRef] [PubMed]

48. Pinho, A.V.; Mawson, A.; Gill, A.; Arshi, M.; Warmerdam, M.; Giry-Laterriere, M.; Eling, N.; Lie, T.; Kuster, E.; Camargo, S.; et al. Sirtuin 1 stimulates the proliferation and the expression of glycolysis genes in pancreatic neoplastic lesions. Oncotarget 2016, 7, 74768-74778. [CrossRef] [PubMed]

49. Lee, E.; Horn-Ross, P.L.; Rull, R.P.; Neuhausen, S.L.; Anton-Culver, H.; Ursin, G.; Henderson, K.D.; Bernstein, L. Reproductive factors, exogenous hormones, and pancreatic cancer risk in the CTS. Am. J. Epidemiol. 2013, 178, 1403-1413. [CrossRef]

50. Boldes, T.; Merenbakh-Lamin, K.; Journo, S.; Shachar, E.; Lipson, D.; Yeheskel, A.; Pasmanik-Chor, M.; Rubinek, T.; Wolf, I. R269C variant of ESR1: High prevalence and differential function in a subset of pancreatic cancers. BMC Cancer 2020, 20, 531. [CrossRef] [PubMed]

51. Satake, M.; Sawai, H.; Go, V.L.; Satake, K.; Reber, H.A.; Hines, O.J.; Eibl, G. Estrogen receptors in pancreatic tumors. Pancreas 2006, 33, 119-127. [CrossRef] [PubMed]

52. Pozios, I.; Knosel, T.; Zhao, Y.; Assmann, G.; Pozios, I.; Muller, M.H.; Bruns, C.J.; Kreis, M.E.; Seeliger, H. Expression of phosphorylated estrogen receptor beta is an independent negative prognostic factor for pancreatic ductal adenocarcinoma. $J$. Cancer Res. Clin. Oncol. 2018, 144, 1887-1897. [CrossRef] [PubMed]

53. Seeliger, H.; Pozios, I.; Assmann, G.; Zhao, Y.; Muller, M.H.; Knosel, T.; Kreis, M.E.; Bruns, C.J. Expression of estrogen receptor beta correlates with adverse prognosis in resected pancreatic adenocarcinoma. BMC Cancer 2018, 18, 1049. [CrossRef] [PubMed]

54. Wu, Y.; Huang, H.; Fervers, B.; Lu, L. Syndecan-1 and KRAS Gene Expression Signature Associates with Patient Survival in Pancreatic Cancer. Pancreas 2020, 49, 1187-1194. [CrossRef] [PubMed]

55. Cooke, P.S.; Nanjappa, M.K.; Ko, C.; Prins, G.S.; Hess, R.A. Estrogens in Male Physiology. Physiol. Rev. 2017, 97, 995-1043. [CrossRef]

56. Hammes, S.R.; Levin, E.R. Impact of estrogens in males and androgens in females. J. Clin. Investig. 2019, 129, 1818-1826. [CrossRef] [PubMed]

57. Xiong, X.; Rao, G.; Roy, R.V.; Zhang, Y.; Means, N.; Dey, A.; Tsaliki, M.; Saha, S.; Bhattacharyya, S.; Dhar Dwivedi, S.K.; et al. Ubiquitin-binding associated protein 2 regulates KRAS activation and macropinocytosis in pancreatic cancer. FASEB J. 2020, 34, 12024-12039. [CrossRef]

58. Risch, H.A.; Yu, H.; Lu, L.; Kidd, M.S. ABO blood group, Helicobacter pylori seropositivity, and risk of pancreatic cancer: A case-control study. J. Natl. Cancer Inst. 2010, 102, 502-505. [CrossRef]

59. Risch, H.A.; Lu, L.; Kidd, M.S.; Wang, J.; Zhang, W.; Ni, Q.; Gao, Y.T.; Yu, H. Helicobacter pylori seropositivities and risk of pancreatic carcinoma. Cancer Epidemiol. Biomark. Prev. 2014, 23, 172-178. [CrossRef]

60. Zambirinis, C.P.; Pushalkar, S.; Saxena, D.; Miller, G. Pancreatic cancer, inflammation, and microbiome. Cancer J. 2014, 20 , 195-202. [CrossRef]

61. Wang, C.; Li, J. Pathogenic Microorganisms and Pancreatic Cancer. Gastrointest. Tumors 2015, 2, 41-47. [CrossRef] [PubMed]

62. Abdelmohsen, K.; Panda, A.C.; Kang, M.J.; Guo, R.; Kim, J.; Grammatikakis, I.; Yoon, J.H.; Dudekula, D.B.; Noh, J.H.; Yang, X.; et al. 7SL RNA represses p53 translation by competing with HuR. Nucleic Acids Res. 2014, 42, 10099-10111. [CrossRef]

63. Nabet, B.Y.; Qiu, Y.; Shabason, J.E.; Wu, T.J.; Yoon, T.; Kim, B.C.; Benci, J.L.; DeMichele, A.M.; Tchou, J.; Marcotrigiano, J.; et al. Exosome RNA Unshielding Couples Stromal Activation to Pattern Recognition Receptor Signaling in Cancer. Cell 2017, 170, 352-366.e313. [CrossRef]

64. Zang, W.; Wang, Y.; Wang, T.; Du, Y.; Chen, X.; Li, M.; Zhao, G. miR-663 attenuates tumor growth and invasiveness by targeting eEF1A2 in pancreatic cancer. Mol. Cancer 2015, 14, 37. [CrossRef]

65. Monteiro, F.L.; Baptista, T.; Amado, F.; Vitorino, R.; Jeronimo, C.; Helguero, L.A. Expression and functionality of histone H2A variants in cancer. Oncotarget 2014, 5, 3428-3443. [CrossRef] 
66. Khare, S.P.; Sharma, A.; Deodhar, K.K.; Gupta, S. Overexpression of histone variant H2A.1 and cellular transformation are related in N-nitrosodiethylamine-induced sequential hepatocarcinogenesis. Exp. Biol. Med. 2011, 236, 30-35. [CrossRef] [PubMed]

67. Ayars, M.; O'Sullivan, E.; Macgregor-Das, A.; Shindo, K.; Kim, H.; Borges, M.; Yu, J.; Hruban, R.H.; Goggins, M. IL2RG, identified as overexpressed by RNA-seq profiling of pancreatic intraepithelial neoplasia, mediates pancreatic cancer growth. Oncotarget 2017, 8, 83370-83383. [CrossRef] [PubMed]

68. Pandha, H.; Rigg, A.; John, J.; Lemoine, N. Loss of expression of antigen-presenting molecules in human pancreatic cancer and pancreatic cancer cell lines. Clin. Exp. Immunol. 2007, 148, 127-135. [CrossRef]

69. Gauvreau, M.E.; Cote, M.H.; Bourgeois-Daigneault, M.C.; Rivard, L.D.; Xiu, F.; Brunet, A.; Shaw, A.; Steimle, V.; Thibodeau, J. Sorting of MHC class II molecules into exosomes through a ubiquitin-independent pathway. Traffic 2009, 10, 1518-1527. [CrossRef]

70. Xiong, Z.; Liu, E.; Yan, Y.; Silver, R.T.; Yang, F.; Chen, I.H.; Chen, Y.; Verstovsek, S.; Wang, H.; Prchal, J.; et al. An unconventional antigen translated by a novel internal ribosome entry site elicits antitumor humoral immune reactions. J. Immunol. 2006, 177, 4907-4916. [CrossRef]

71. Evangelou, P.; Groll, M.; Oppermann, H.; Gaunitz, F.; Eisenloffel, C.; Muller, W.; Eschrich, K.; Schanzer, A.; Nestler, U. Assessment of ApoC1, LuzP6, C12orf75 and OCC-1 in cystic glioblastoma using MALDI-TOF mass spectrometry, immunohistochemistry and qRT-PCR. Med. Mol. Morphol. 2019, 52, 217-225. [CrossRef]

72. Zhang, Y.; Sun, J.; Li, F.; Grogan, T.R.; Vergara, J.L.; Luan, Q.; Park, M.S.; Chia, D.; Elashoff, D.; Joshipura, K.J.; et al. Salivary extracellular RNA biomarkers for insulin resistance detection in hispanics. Diabetes Res. Clin. Pract. 2017, 132, 85-94. [CrossRef]

73. Glauert, H.P.; Elliott, R.S.; Han, S.G.; Athey, M.; Lee, E.Y.; Gairola, C.G. Effect of cigarette smoke exposure and mutant Kras overexpression on pancreatic cell proliferation. Oncol. Lett. 2017, 13, 1939-1943. [CrossRef] [PubMed]

74. Risch, H.A.; Yu, H.; Lu, L.; Kidd, M.S. Detectable Symptomatology Preceding the Diagnosis of Pancreatic Cancer and Absolute Risk of Pancreatic Cancer Diagnosis. Am. J. Epidemiol. 2015, 182, 26-34. [CrossRef] [PubMed]

75. Chhoda, A.; Lu, L.; Clerkin, B.M.; Risch, H.; Farrell, J.J. Current Approaches to Pancreatic Cancer Screening. Am. J. Pathol. 2019, 189, 22-35. [CrossRef] [PubMed]

76. Li, S.; Li, Y.; Chen, B.; Zhao, J.; Yu, S.; Tang, Y.; Zheng, Q.; Li, Y.; Wang, P.; He, X.; et al. exoRBase: A database of circRNA, lncRNA and mRNA in human blood exosomes. Nucleic Acids Res. 2018, 46, D106-D112. [CrossRef] [PubMed]

77. Li, Y.; Zheng, Q.; Bao, C.; Li, S.; Guo, W.; Zhao, J.; Chen, D.; Gu, J.; He, X.; Huang, S. Circular RNA is enriched and stable in exosomes: A promising biomarker for cancer diagnosis. Cell Res. 2015, 25, 981-984. [CrossRef] [PubMed]

78. Yu, S.; Li, Y.; Liao, Z.; Wang, Z.; Wang, Z.; Li, Y.; Qian, L.; Zhao, J.; Zong, H.; Kang, B.; et al. Plasma extracellular vesicle long RNA profiling identifies a diagnostic signature for the detection of pancreatic ductal adenocarcinoma. Gut 2020, 69, 540-550. [CrossRef]

79. Yang, J.C.; Risch, E.; Zhang, M.; Huang, C.; Huang, H.; Lu, L. Association of tRNA methyltransferase NSUN2/IGF-II molecular signature with ovarian cancer survival. Future Oncol. 2017, 13, 1981-1990. [CrossRef] [PubMed]

80. Lu, L.; Zhu, G.; Zeng, H.; Xu, Q.; Holzmann, K. High tRNA Transferase NSUN2 Gene Expression is Associated with Poor Prognosis in Head and Neck Squamous Carcinoma. Cancer Investig. 2018, 36, 246-253. [CrossRef] [PubMed] 